\title{
Correction to: A Concise Note on Deformation Twinning and Spall Failure in Magnesium at the Extremes
}

\author{
C. L. Williams ${ }^{1}$ (D) D. D. Mallick ${ }^{1}$ J. W. Wilkerson ${ }^{2}$
}

Published online: 10 September 2020

(c) Society for Experimental Mechanics, Inc 2020

\section{Correction to: Journal of Dynamic Behavior of Materials https://doi.org/10.1007/s40870-020-00261-9}

The original article was updated to switch captions in Fig. 3 as Rolling Direction (Pretwinned Compression) and Normal Direction (Pretwinned Tension).

Publisher's Note Springer Nature remains neutral with regard to jurisdictional claims in published maps and institutional affiliations.

The original article can be found online at https://doi.org/10.1007/ s40870-020-00261-9.

\section{L. Williams}

cyril.1.williams.civ@mail.mil

1 US Army CCDC Army Research Laboratory, 321 Colleran Road, Aberdeen Proving Ground, MD 21005-5066, USA

2 J. Mike Walker '66 Department of Mechanical Engineering, Texas A\&M University, College Station, TX 77843, USA 